\title{
Disease-Associated Plasmacytoid Dendritic Cells
}

\author{
Shuang $\mathrm{Li}^{1 \dagger}$, Jing $\mathrm{Wu}^{1 \dagger}$, Shan $\mathrm{Zhu^{1 }}$, Yong-Jun Liu${ }^{1,2}$ and Jingtao Chen ${ }^{1 *}$ \\ ${ }^{1}$ Institute of Translational Medicine, The First Hospital, Jilin University, Changchun, China, \\ ${ }^{2}$ Sanofi Research and Development, Cambridge, MA, United States
}

OPEN ACCESS

Edited by:

John Isaacs,

Newcastle University, United

Kingdom

Reviewed by:

Lennart T. Mars,

Institut national de la santé et de la recherche médicale, France Albert Rizvanov, Kazan Federal University, Russia Muzlifah Aisha Haniffa,

Newcastle University, United Kingdom

*Correspondence: Jingtao Chen jtchen@jlu.edu.cn

tThese authors have contributed equally to this work.

Specialty section: This article was submitted to Immunological Tolerance and Regulation, a section of the journal Frontiers in Immunology

Received: 24 November 2016 Accepted: 22 September 2017

Published: 16 October 2017

Citation:

Li S, Wu J, Zhu S, Liu Y-J and Chen J (2017) Disease-Associated

Plasmacytoid Dendritic Cells.

Front. Immunol. 8:1268. doi: 10.3389/fimmu.2017.01268
Plasmacytoid dendritic cells (pDCs), also called natural interferon (IFN)-producing cells, represent a specialized cell type within the innate immune system. pDCs are specialized in sensing viral RNA and DNA by toll-like receptor-7 and -9 and have the ability to rapidly produce massive amounts of type 1 IFNs upon viral encounter. After producing type 1 IFNs, pDCs differentiate into professional antigen-presenting cells, which are capable of stimulating $T$ cells of the adaptive immune system. Chronic activation of human pDCs by self-DNA or mitochondrial DNA contributes to the pathogenesis of systemic lupus erythematosis and IFN-related autoimmune diseases. Under steady-state conditions, pDCs play an important role in immune tolerance. In many types of human cancers, recruitment of pDCs to the tumor microenvironment contributes to the induction of immune tolerance. Here, we provide a systemic review of recent progress in studies on the role of pDCs in human diseases, including cancers and autoimmune/inflammatory diseases.

Keywords: plasmacytoid dendritic cells, dysregulation, malignancy, autoimmune disease, tumor microenvironment

\section{INTRODUCTION}

Plasmacytoid dendritic cells (pDCs) were first described in 1958 by pathologists Lennert and Remmele (1). Human pDCs are often identified and classified based on the coexpression of CD123 and CD303, whereas mouse pDCs express B220 and CD11c. pDCs recognize RNA and DNA viruses through toll-like receptor (TLR)-7 and -9, leading to activation of pDCs, and release high amounts of type I interferon (IFN-I) (2). Activated pDCs express high levels of major histocompatibility complex class II (MHC II), and costimulatory molecules (CD40, CD80, CD83, and CD86) enable pDCs to act as antigen-presenting cells to present antigens to $\mathrm{CD} 4^{+} \mathrm{T}$ cells. Moreover, $\mathrm{pDCs}$ secrete other proinflammatory cytokines and chemokines, such as interleukin-6 (IL-6), IL-12, CXC-chemokine ligand 8 (CXCL8), CXCL10, CC-chemokine ligand 3 (CCL3), and CCL4. Thus, the biology of pDCs is multifaceted $(2,3)$.

Plasmacytoid dendritic cells were originally derived from bone marrow hematopoietic stem cells (HSCs) (4). In the presence of Fms-like tyrosine kinase ligand (Flt3L) and Flt3L receptor signaling, HSCs could differentiate into pDCs and other DC subsets, such as conventional dendritic cells (5). In the presence of some special factors, such as IFN regulatory factor 8 (IRF8), E2-2, basic leucine zipper transcription factor ATF-like 3 (Batf3), and IFN-I, molecular signaling restricts the development of common lymphoid progenitor and common myeloid progenitor (CMP) lineages into pDCs $(2,6,7)$. Recently, Reis and Sousa's group demonstrated that besides CMP, human pDCs could also arise from multipotent lymphoid progenitors (MLPs). Compared with CMPs, MLPs show better potential for $\mathrm{pDC}$ production (8). The biology of pDCs is multifaceted, and analysis of the different origins of pDCs may help to explain the biology of pDCs and their functional heterogeneity in health 
and disease; however, further studies are needed to explore these aspects of pDC biology.

After leaving the bone marrow, blood pDCs directly migrate into primary lymphoid organs and reach T cell-rich areas of secondary lymphoid tissues via high endothelial venules (HEVs) in lymph nodes and mucosa-associated lymphoid tissues. Normally, pDCs are limited to primary and secondary lymphoid organs; however, under pathological conditions, functional chemotactic receptors expressed on circulating pDCs interact, and the corresponding ligands expressed by lymph nodes and non-lymphoid tissues facilitate pDCs trafficking to lymph nodes and diseased tissues through HEVs $(9,10)$.

\section{pDCs IN TUMOR MICROENVIRONMENTS}

Malignant cells strongly interact with their microenvironment and modulate the cells in this niche to promote tumor growth and metastasis. The circulating pDCs recruited into the tumor microenvironment are characterized by decreased expression of costimulatory molecules and a reduced ability to produce IFN-I. Similarly, pDCs frequently display an inhibitory phenotype and promote a tolerogenic microenvironment through the activation of regulatory T cells (Tregs) (11). Malignant-derived immunosuppressive factors facilitate the infiltration of pDCs into disease tissue and interact with components derived from $\mathrm{pDCs}$ to inhibit the immune response. Tumor-associated pDCs then respond to malignant-derived immunosuppressive factors during the disease process through regulatory factors from TLR-7/9 signaling pathways and components produced by $\mathrm{pDCs}$. Thus, pDCs promote tumor progression and attenuate immune regression $(12,13)$.

There are several mechanisms mediating the pathogenicity of disease-associated pDCs in different tumors. One of these mechanisms is inhibition of IFN-I, IL-6, tumor necrosis factor (TNF)- $\alpha$, and IFN-inducible protein-10 (IP-10) release. Regulatory factors are expressed by pDCs via TLR-7/9 pathway, causing the signaling to proceed in the wrong direction and resulting in dysfunctional secretion of IFN-I e.g., IRF7 (14-16), indoleamine 2,3-dioxygenase (IDO) $(17,18)$, and immunoglobulin-like transcript 7 (ILT7) (19). In comparison, IFN-I secretion is also strongly disrupted by factors present in the disease microenvironment derived from necrotic cells or other immune cells, such as prostaglandin E2 (PGE2) (20), transforming growth factor beta (TGF- $\beta$ ) (21), IL-3 (22, 23), IL-10 (24), vasoactive intestinal peptide (VIP) (25), Wnt5a $(26,27)$, and high-mobility group box-1 protein (HMGB1) (28). In the second escape strategy, immunosuppression mediators decrease levels of costimulatory molecules and cause accelerated production of $\mathrm{pDCs}$ with immature characteristics, as demonstrated by VIP, Wnt5a, TNF- $\alpha$, and HMGB1 (11). A third mechanism is via interactions between pDCs and other immune cells or malignant cells, wherein pDCs inhibit CD4 and CD8 T-cell proliferation and induce the differentiation of IL-10producing $\mathrm{T}$ cells. Associated immaturity and coinhibitory molecules include IL-6, IL-8, CXCL12, HMGB1, IDO, ICOSL (29), granzyme B, OX40L, B-cell activating factor (BAFF), receptor activator of nuclear factor kappa B (RANK) (22), and granulocyte macrophage colony-stimulating factor (GM-CSF) (30).

In the following sections, we will discuss the functional significance of pDCs in various tumors and their role in mediating immunosuppression in the tumor microenvironment (Table 1). Thus, understanding the regulation of these mechanisms may contribute to the development of strategies to overcome tolerance in the tumor microenvironment.

\section{Melanoma}

Plasmacytoid dendritic cells have been shown to accumulate in the sentinel and metastatic lymph nodes in melanoma (31). Circulating pDCs from patients with melanoma have been found

TABLE 1 | Changes in PDCs in different diseases.

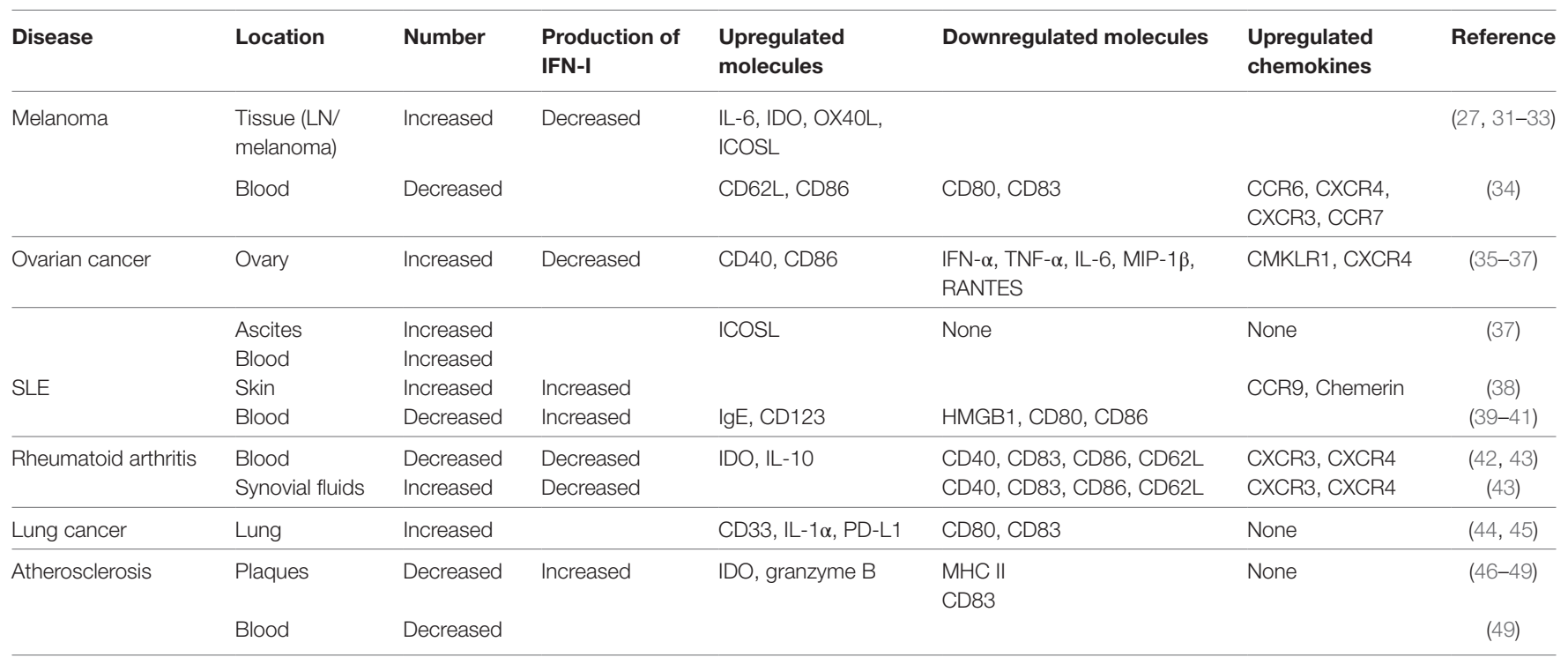

SLE, systemic lupus erythematosus; IDO, indoleamine 2,3-dioxygenase; ICOSL, inducible costimulator ligand; TGF- $\beta$, transforming growth factor beta; LN, lymph node. 
to express higher amounts of CCR6 and CXCR4, while their corresponding ligands CCL20 and CXCL12 are expressed on melanoma cells, suggesting that the CCR6/CCL20 and CXCR4/ CXCL12 axes promote $\mathrm{pDC}$ migration from blood to melanoma foci $(27,34,50,51)$. Remarkably, CCL17, CCL22, and matrix metalloproteinase- 2 found in the melanoma microenvironment have been shown to be associated with pDC accumulation (32). Some studies have also shown that pDCs migrating into the melanoma microenvironment are associated with early relapse and poor prognosis $(26,27,30,31)$.

Mediators of the tumor microenvironment act on tumorinfiltrating pDCs directly to suppress the production of IFN-I and mediate immunosuppression. Melanoma cells produce the immunosuppressive cytokines PGE2, IL-10, and TGF- $\beta$, which directly suppress IFN-I production by inhibiting TLR-7/9 and IRF7 expression on pDCs. Moreover, melanoma cells express Wnt5a, which inhibits TLR-mediated pDC activation and IFN-I production. Wnt5a potentiates melanoma metastasis via induction of the epithelial-to-mesenchymal transition in a protein kinase C-dependent manner $(26,27)$ (Figure 1A). IFN-I production may also be inhibited by ILT7, a ligand combined with BST2, which is expressed on melanoma cells. pDCs preferentially express ILT7, and the interaction between ILT7 and BST2 is involved in pDC and tumor crosstalk $(52,53)$.
Besides low IFN- $\alpha$ production, immunosuppressive mediators secreted by pDCs induce Tregs or suppress Th2 cell secretion to prevent an effective antitumoral response. pDCs in the tumor site express the immune-suppression molecules OX40L and ICOSL, which support melanoma progression (30). pDC infiltration is strongly associated with primary melanoma cell expression of activated signal transducer and activator of transcription 3, which is constitutively expressed in cancer and is thought to be a significant mediator of tumor-induced immunosuppression (31). Melanoma-associated pDCs have been shown to express high levels of IDO, suggesting that melanoma-derived signals may block pDC activation, thereby contributing to immune evasion $(27,31,54,55)$ (Figure 1B). Moreover, pDCs in the tumor microenvironment trigger IL-5/IL-13-secreting Th2 cells and IL-10-secreting Tregs through the expression of OX40L and ICOSL. These cytokines may inhibit cytotoxic T-cell functions and directly favor melanoma growth (32) (Figure 1C).

The interaction between tumor-infiltrating pDCs and other immune cells results in immunosuppression. MHC II molecules on melanoma cells bind to lymphocyte-activated gene 3 (LAG3) expressed on the surface of $\mathrm{pDCs}$, resulting in their tolerogenic activation. Accordingly, LAG3 ${ }^{+}$pDCs display a slightly activated phenotype and produce IL-6 in vivo. IL-6 production by pDCs induces CCL2 production by monocytes. CCL2 is an essential

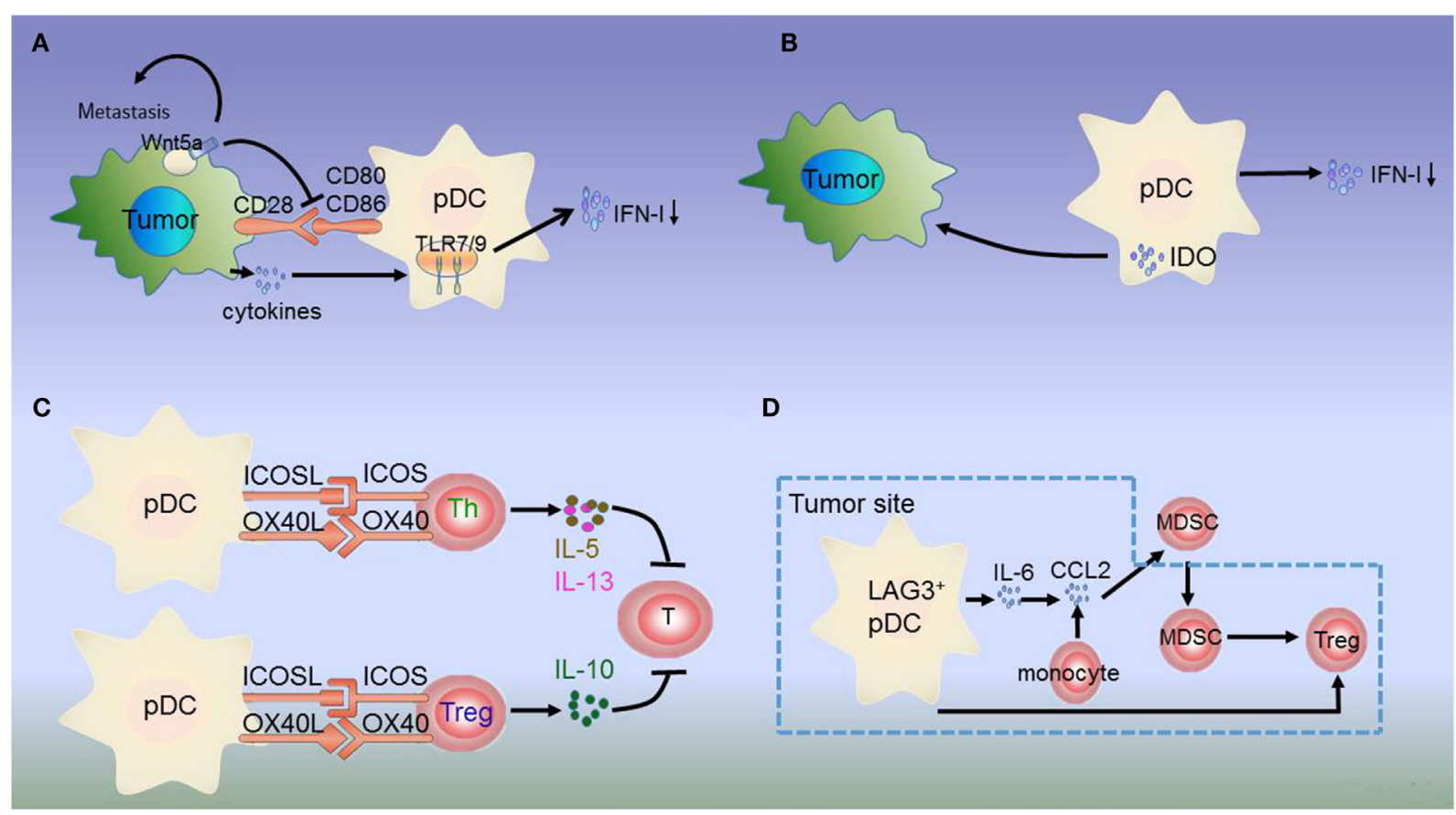

FIGURE 1 | Dysregulation of plasmacytoid dendritic cells (pDCs) in melanoma. (A) Melanoma cells produce the immunosuppressive cytokines prostaglandin E2 (PGE2), interleukin-10 (IL-10), and transforming growth factor beta (TGF- $\beta$ ), which directly suppress type I interferon (IFN-I) production by inhibiting toll-like receptor (TLR) expression on pDCs. Additionally, melanoma-associated pDCs express Wnt5a, which blocks the upregulation of the activation markers CD80 and CD86 on human pDCs and inhibits toll-like receptor (TLR)-mediated pDC activation and production. Wnt5a can also promote melanoma metastasis. This inhibits antitumor function depending on IFN-I. (B) IDO expression in pDCs promotes immune evasion by the tumor. (C) Resident pDCs trigger IL-5/IL-13-secreting Th2 cells and IL-10-secreting Tregs through OX40L/OX40 and ICOSL/ICOS interactions. These cytokines inhibit cytotoxic T cell function and directly favor melanoma growth. (D) LAG3+ pDCs produce IL-6 without inducing IFN-I. pDC-derived IL-6 induces the production of CCL2-a key chemokine in the recruitment of myeloid-derived suppressor cells (MDSCs) - at the tumor site. LAG3+ pDCs and migratory MDSCs induce Tregs directly. Thus, through this alternative activation, LAG3+ pDCs promote immunosuppression. 
chemokine that functions during the recruitment of myeloidderived suppressor cells (MDSCs) to the tumor site. Hence, the recruitment of $\mathrm{LAG}^{+}$pDCs into the tumors and their activation in the absence of IFN-I production drive MDSC-mediated immune suppression $(56,57)$ (Figure 1D). As such, the counterregulatory immune mechanisms in melanoma exhibit extensive signaling crosstalk. IDO is expressed by pDCs, whereas MDSCs, programmed death ligand 1 (PD-L1) ${ }^{+}$T cells, and CTLA $-4^{+}$Tregs are strongly interconnected and associated with advanced disease and negative outcome. Thus, combination treatments targeting these markers can lead to a synergistic response $(55,58)$.

\section{Hematological Malignancies}

Various types of leukemia, multiple myeloma (MM), and malignant lymphoma are collectively defined as hematological malignancies. Among these hematological malignancies, pDCs have been reported to be mostly associated with the pathophysiology of MM, chronic lymphocytic leukemia (CLL), and chronic myelomonocytic leukemia.

\section{Multiple Myeloma}

Plasmacytoid dendritic cells from patients with MM exhibit increased numbers in the bone marrow compared with those in normal donors; moreover, $\mathrm{pDCs}$ are more frequently localized in MM bone marrow than in MM peripheral blood, representing a functional impairment $(22,59)$. The interaction between pDCs (BDCA2) and MM cells (CD138) increases the production of cytokines and chemokines, which can not only prolong the survival of pDCs but also confer growth, survival, and drug resistance in MM cells (59). Finally, pDC-MM cells surface receptor-ligand interactions (BAFF/APRIL and RANK/RANKL) trigger MM cell growth/survival through the nuclear factor (NF)- $\mathrm{B}$ pathway. Thus, cytokines, chemokines, and direct contact between $\mathrm{pDC}$ and MM cells may play critical roles in mediating pDC survival and MM cell growth (22). Ray et al. further demonstrated that treatment with a TLR-9 agonist restored the ability of MM patient-pDCs to stimulate T-cell proliferation and enhance the cytotoxicity of bortezomib (60).

Multiple myeloma cells produce low levels of IL-3. However, when cocultured with pDCs, IL-3 secretion is increased. In vitro and in vivo studies have revealed that IL-3 can prolong $\mathrm{pDC}$ survival (22). Ray et al. recently demonstrated that SL-401, a novel anti-IL-3R antibody, blocks pDC-induced MM cell growth by targeting pDCs (59). These studies therefore validated the targeting of pDC-MM interactions as a therapeutic strategy to overcome drug resistance in MM.

Microenvironmental interactions between pDCs and other immune cells could lead to a poor prognosis in MM and promote tumor cell growth and survival indirectly. Additionally, the increased numbers of pDCs in the bone marrow of MM patients enhances Th2 2 cell polarization through TNF- $\alpha$ and IL- 6 secretion. Th2 2 cells contribute to the increased abundance of IL-22 + IL-13 ${ }^{+} \mathrm{T}$ cells, thereby leading to poor prognosis in MM based on the effects of pDCs in the tumor microenvironment (61).

\section{Chronic Lymphocytic Leukemia}

Lower numbers of pDCs cells are found in the peripheral blood and bone marrow of patients with progressive CLL and functional impairments $(62,63)$. IFN-I production is attenuated owing to decreased TLR-9 expression by pDCs, resulting in dampened effector immune cell activity (63). In addition, factors derived from the tumor microenvironment facilitate the dysfunction of pDCs in CLL. Vascular endothelial growth factor (VEGF) receptor neuropilin-1 (NRP1) is a critical link between angiogenesis and immune tolerance. VEGF overexpression has been established in CLL and has been shown to stimulate higher NRP1 expression. Accordingly, the expression of NRP1 has been found to be considerably higher in pDCs from patients with CLL compared with those in healthy volunteers. This increased NRP1 expression mediates tumor escape from immune surveillance $(64,65)$. However, few studies have assessed the relationships among pDCs, tumor cells, and other immune cells in CLL, and more in-depth investigations are needed to explore these mechanisms further.

\section{Breast Cancer and Ovarian Cancer}

Breast cancer and ovarian cancer frequently occur in women. Most patients present with metastases, leading to increased numbers of dysfunctional pDCs at both primary and metastatic sites, such as the bone or enterocyte (28). pDC infiltration in primary localized breast cancer is correlated with poor survival, suggesting that these immune cells may contribute to tumor progression and tumor metastases $(35,66)$.

\section{Breast Cancer}

In breast cancer, pDCs exhibit a slightly activated phenotype and produce decreasing amounts of IFN-I after TLR activation in vitro compared with pDCs from healthy human peripheral blood. One study showed that the synergistic response of TGF- $\beta$ and TNF- $\alpha$ is an important in vivo mechanism blocking IFN-I production by tumor-associated pDCs through the inhibition of IRF7 signaling and nuclear translocation in gynecological malignancy. This finding indicated that targeting tumor-associated $\mathrm{pDCs}$ to restore their IFN- $\alpha$ production may be a promising strategy, achieved by combining TLR-7/9-based immunotherapy with TGF- $\beta$ and TNF- $\alpha$ antagonists, in breast cancer (67). Interestingly, partial tumor-associated pDCs cause selective suppression of IFN-I production and possess the unique capacity to sustain the expansion of FoxP3 ${ }^{+}$Treg cells, which may contribute to breast cancer progression (68).

Certain relevant mechanisms of pDCs not only depend on IFN-I but also function as immunosuppression mediators to induce tumor progression through the receptor/ligand axis. In breast carcinoma, tumor-associated pDC expression of ICOSL drives the expansion and suppressive function of ICOS $^{+}$Tregs, leading to preferential accumulation of this Treg subset in the close vicinity of pDCs in the tumor microenvironment and a secretion of the immunosuppressive mediator IL-10 by stimulation with tumor-associated antigen (TAA). These results showed that the ICOS/ICOS-L interaction is a central event in immunosuppression of tumor-associated $\mathrm{T}$ cells. Thus, the infiltration of pDCs in neoplastic lesions favors the establishment of a tumor microenvironment by the activation and expansion of ICOS $^{+}$ Tregs, accelerating disease progression $(13,69)$. Another crucial factor inducing tumor progression in breast cancer is GM-CSF, via the GM-CSF/pDC axis. GM-CSF produced by primary 
breast tumor cells induces the activation of pDCs expressing the GM-CSF receptor. The GM-CSF/pDC axis is also significantly associated with more aggressive breast cancer subtypes (30).

Breast cancer differs from other malignancies in its specific dissemination pattern. In breast carcinoma, increasing infiltration of pDCs is related to high levels of IL-3, IL-6, IL-10, IL-15, IP-10, monocyte chemotactic protein-1, and RANTES $(66,70)$. Besides being immunosuppressive, these chemokines and cytokines are known to directly or indirectly induce tumor metastasis. These soluble factors induce the expression of RANKL, which is important for osteoclast-mediated bone resorption, thereby helping metastatic cells to grow $(66,71)$. Upon breast cancer dissemination, there is a steady increase in pDCs numbers within the bone, resulting in a sustained Th2 response along with elevated levels of Tregs and MDSCs. Subsequently, $\mathrm{pDCs}$ and $\mathrm{CD} 4^{+} \mathrm{T}$ cells produce osteolytic cytokines and cause severe bone damage $(66,72,73)$.

\section{Ovarian Cancer}

In ovarian cancer, $\mathrm{pDCs}$ were reported to be attracted to primary ovarian cancer and ascites through stromal-derived factor-1 (SDF-1)/CXCL12 $(36,74,75)$. In addition, SDF-1 attracts pDCs to the tumor environment, where they induced angiogenesis through production of TNF- $\alpha$ and IL- 8 to promote ovarian tumor angiogenesis (74).

Gilliet et al. found that the numbers of Foxp $3^{+}$Tregs accumulating in the tumor microenvironment of ovarian cancers could be attributed to the expression of ICOS on Tregs. Moreover, the expansion and suppressive functions of Tregs are strictly dependent on ICOSL costimulation provided by tumor-associated pDCs. Accordingly, $\mathrm{ICOS}^{+}$Tregs were found to localize near tumor pDCs, and the number of Tregs is directly correlated with the numbers of $\mathrm{pDC}$ in the tumors. These findings suggest an important role for the interaction between $\mathrm{ICOSL}^{+} \mathrm{pDCs}$ and $\mathrm{ICOS}^{+}$ Foxp $3^{+}$Tregs, leading to tumor progression in ovarian cancer (35). Another Treg subset in ovarian cancers induced by pDCs is CD8 ${ }^{+}$Tregs. CD8 ${ }^{+}$Tregs significantly suppress myeloid dendritic cell-mediated TAA-specific $\mathrm{T}$ cell effector functions through IL-10 (36). In general, breast cancer and ovarian cancer have similar mechanisms for both tumor promotion and metastases.

Interestingly, a clinical trial indicated that $\mathrm{pDCs}$ might have a subtle relationship with sex (76-79). The production of IFN- $\alpha$ in response to pDCs via TLR-7 activation is higher in the presence of estrogens, indicating that estrogens may be an attractive target for specific regulation of this pathway (80). A recent study suggested that estrogens regulate $\mathrm{pDC}$ IFN-I production through IRF5, which may act by enhancing IFN- $\alpha$ production in synergy with IRF7 (81). Besides the role of estrogens, X-linked genetic factors could also be involved in the sex-dependent differences in the TLR-7-mediated responses of pDCs. The TLR-7 gene is located on the $\mathrm{X}$ chromosome. While no sex-based biases have been observed linking pDCs with neoplastic disease, these cells are significantly associated with more aggressive gynecological carcinomas $(30,37)$.

\section{Hepatocellular Carcinoma (HCC)}

Hepatocellular carcinoma is the most common type of liver cancer; however, the role of pDCs in HCC is not clear. Recent studies have demonstrated that the numbers of pDCs are increased in tumor tissue and decreased in blood of patients with HCC (82, $83)$, suggesting that peripheral pDCs migrate to liver lesions in patients with HCC. In addition, pDCs exposed to tumor-derived factors would enhance IL-10 production by CD4 ${ }^{+}$Tregs through upregulation of ICOSL (83). This can help tumor cells escape the immune system. In vitro, HSC-derived pDC-based vaccines are highly potent inducers of tumor-reactive T-cell and NK cell responses (84). These finding may provide insights into appropriate immunotherapies for HCC using pDCs.

\section{Gastrointestinal Cancer (GC)}

To date, few studies have explored the role of pDCs in GC. Yu et al. found a positive correlation between $\mathrm{pDCs}$ and $\mathrm{ICOS}^{+}$Tregs in peripheral blood and peritumor tissue from patients with GC (12). Additionally, Yang et al. demonstrated that $\mathrm{CD}_{12} 3^{+} \mathrm{pDCs}$ in tumor tissue and tumor draining lymph nodes may contribute to Treg development and promote tumor tolerance in the colorectal cancer (CRC) tolerogenic milieu (85). Briefly, pDCs play a potential role in recruiting Tregs, and both participate in the immunosuppression microenvironment of GC and CRC.

\section{Lung Cancer}

Studies of pDCs in lung cancer have mostly focused on nonsmall cell lung carcinoma (NSCLC). The proportion of pDCs is significantly increased in the peripheral blood and tumor tissues of patients with NSCLC $(44,45)$.

In NSCLC, pDCs show immunosuppressive phenotypes, as determined by higher levels of CD33 and PD-L1. Based on the characteristics of lung tumor-associated pDCs, pDCs are able to produce high levels of IL- $1 \alpha$ in an AIM2-dependent manner, facilitating tumor cell proliferation in the lung (45). Moreover, a study of pDCs in NSCLC patients with different clinical stages demonstrated that elevated pDC numbers were observed in cases with higher disease stages (III/IV) compared with those in cases with lower stages (I/II) (44), suggesting a close relationship between tumor-associated pDCs and tumor progression (86). Interestingly, patients with NSCLC who smoke exhibited elevated pDC numbers compared with those of nonsmokers (44). Exploring the role of pDCs in lung cancer may lead to the development of novel therapeutic strategies.

\section{AUTOIMMUNE DISEASE}

Aberrant pDC function has been shown to be involved in psoriasis, systemic lupus erythematosus (SLE), and rheumatoid arthritis (RA). Autoimmune disease arises from an abnormal immune response of the body against certain substances and normal tissues under physiological conditions. Notably, peripheral pDCs and conventional DCs are significantly reduced in patients with autoimmune diseases (87-91); however, an increased number of pDCs has been found in human tissue lesions $(92,93)$. These findings could be attributed to the role of pDCs in inflamed tissue; in autoimmune disease, these cells are recruited from the blood (94). pDCs are normally absent from the skin. However, they accumulate in inflammatory dermatoses from peripheral blood, where they organize local immune responses (94-96). 
Several chemokines expressed on pDCs have been shown to participate in migration from the peripheral blood to tissue lesions. In psoriasis and SLE, chemerin is abundantly produced by HEVs in reactive lymph nodes, whereas skin-infiltrating pDCs strongly express ChemR23 in pathological conditions. pDCs may be recruited to disease foci through the chemerin/ ChemR23 axis (97-99). Moreover, in RA, CXCR3, CXCR4, and CCR7 are expressed on both blood-derived pDCs and synovial tissue-derived pDCs. Their corresponding ligands, CXCL-10, CXCL-11, and CXCL-12, are present in RA and multiple sclerosis and stimulate the chemotaxis of blood-derived pDCs $(43,100$, 101). Here, we discuss the roles of pDCs in SLE and other autoimmune diseases, include psoriasis, RA, and type I diabetes (T1Ds).

\section{Systemic Lupus Erythematosus}

In autoimmunity, pDCs may exhibit both immunogenic and tolerogenic functions according to the development of inflammatory autoimmune disorders (102). Accumulating evidence has suggested that pDCs can aggravate disease development in autoimmune disease, and this immunogenic function appears to be mediated partly by the overproduction of the inflammationspecific cytokine IFN-I $(39,103)$. IFN-I hyperproduction by pDCs is involved in the pathogenesis of SLE (104) (Figure 2A). Accordingly, the production of IFN-I depends on changes in the functions of mediators derived from autologous pDCs and lesion cells. For example, activation of IFN-I occurs via HMGB1 secreted by necrotic cells and inflammatory cells. HMGB1 then interacts with the receptor for generation of advanced glycation end products, which induces the activation of pDCs via the TLR9-MyD88 pathway (105).

In addition, IFN-I overproduction may induce feedback regulation to target $\mathrm{pDC}$ or other immune cells. In healthy individuals, $\mathrm{pDCs}$ promote the differentiation of immature B cells into IL-10-producing Bregs with stimulation by high concentrations of IFN- $\alpha$, which subsequently suppresses IFN- $\alpha$ production by pDCs via IL-10 release. In SLE, despite aberrant Breg function, IFN- $\alpha$ overexpression may still result in regulatory feedback between pDCs and Bregs. Thus, altered pDC-Breg interactions contribute to the pathogenesis of SLE (106). IFN-I can also upregulate serum lupus autoantigens, such as Ro52 and laminin-1b, which could influence SLE progression $(107,108)$. Therefore, analysis of the functions of pDCs in SLE can help to develop new therapeutic strategies.

\section{Other Autoimmune Diseases}

Interferon I production by pDCs also plays an immunogenic role in other autoimmune diseases. LL37, an antimicrobial peptide that is highly expressed in psoriatic lesions, binds self-DNA to form aggregated and condensed structures that are potent activators of pDCs in vitro. These complexes are delivered to $\mathrm{pDCs}$ to trigger TLR-9 expression and local IFN-I production (109). As a result, IFN-I released from pDCs in tissue lesions initiates the autoimmune T-cell cascade, facilitating autoimmunity (110).

In contrast to the immunogenic function of $\mathrm{pDCs}$, increasing evidence has supported that unstimulated or alternatively stimulated pDCs can act as tolerogenic cells in autoimmune disease. Siglec-H is a surface molecule specifically expressed on mouse pDCs. Siglec-H-mediated antigen delivery was found to induce a hyporesponsive state in $\mathrm{CD}^{+} \mathrm{T}$ cells, leading to reduced expansion and inhibition of Th cell-dependent immunity (111). In addition, in the disease microenvironment, IL-3 and CD40L can activate $\mathrm{pDC}$ precursors, which are able to induce the differentiation of IL-10-producing $\mathrm{CD}^{+}$Tregs (112-114). In patients with juvenile idiopathic arthritis and cutaneous lupus erythematosus, pDCs can secrete large amounts of granzyme B in response to immunomodulatory cytokines, such as IL-3, IL-10, and IL-21. Moreover, pDC-derived granzyme B suppresses T-cell proliferation in a cell contact-dependent manner, similar to Tregs $(115,116)$ (Figure 2C). IDO can suppress the antigen-presenting ability of pDCs (117). In addition, studies have demonstrated that IDO can induce tolerogenic pDC function, although the underlying mechanism needs to be evaluated in animal models $(42,118)$ (Figure 2B).

Plasmacytoid dendritic cell function is tightly regulated in immune disorders by iNKT cells. pDCs are an essential partner of iNKT cells in T1D. Upon viral infection, iNKT cells induce TGF- $\beta$-producing $\mathrm{pDCs}$ in the pancreatic lymph nodes. These tolerogenic pDCs convert naive anti-islet $\mathrm{T}$ cells into Foxp $3^{+} \mathrm{CD}^{+}$Tregs in pancreatic lymph nodes. Tregs are then recruited to pancreatic islets, where they produce TGF- $\beta$, which dampens the activity of viral- and islet-specific $\mathrm{CD}^{+}$ $\mathrm{T}$ cells, thereby preventing T1D development in animal models (119-121) (Figure 2D).

Plasmacytoid dendritic cells exhibit different functional mechanisms during the development of inflammatory autoimmune disorders. Immunogenic pDC functions contribute to disease pathogenesis, e.g., SLE, through IFN-I production; however, tolerogenic pDCs may promote self-antigen-specific $\mathrm{CD}^{+} \mathrm{T}$-cell tolerance and induce Treg differentiation, as observed in RA and T1D. Further studies of pDCs functional mechanisms in different diseases may facilitate the development of novel therapies.

\section{THERAPEUTIC PROSPECTS}

Plasmacytoid dendritic cells induce immunosuppression and immune tolerance, thereby promoting disease progression. Potential solutions for disruption of tolerance include controlling IFN-I production by blocking IDO or TLR pathway activation or suppression of other inhibition molecules. IDO is highly expressed on pDCs when stimulated with IFN-I and TLR agonists in leukemia. Yamahira et al. investigated the effects of a novel IDO inhibitor, Toho-1, and found that it is efficient for potentiating antigen presentation of $\mathrm{pDCs}$ and may be applicable for $\mathrm{pDC}$-based immunotherapy in tumors and severe viral infections (122).

Plasmacytoid dendritic cells are also thought to be involved in the pathogenesis of tumor and autoimmunity characterized by IFN-I via TLR-7/9 ligands in breast cancer and melanoma $(123,124)$. In melanoma treatment using the TLR-7 agonist imiquimod, infiltrating $\mathrm{pDCs}$ are capable of producing IFN- $\alpha$ and inducing complete regression or significant reduction of melanomas (11, 123, 125-127). Moreover, the TLR-9 agonist CpG activates the TLR signaling pathway and inhibits tumor growth in both breast cancer and melanoma mouse models $(76,124,128)$. 


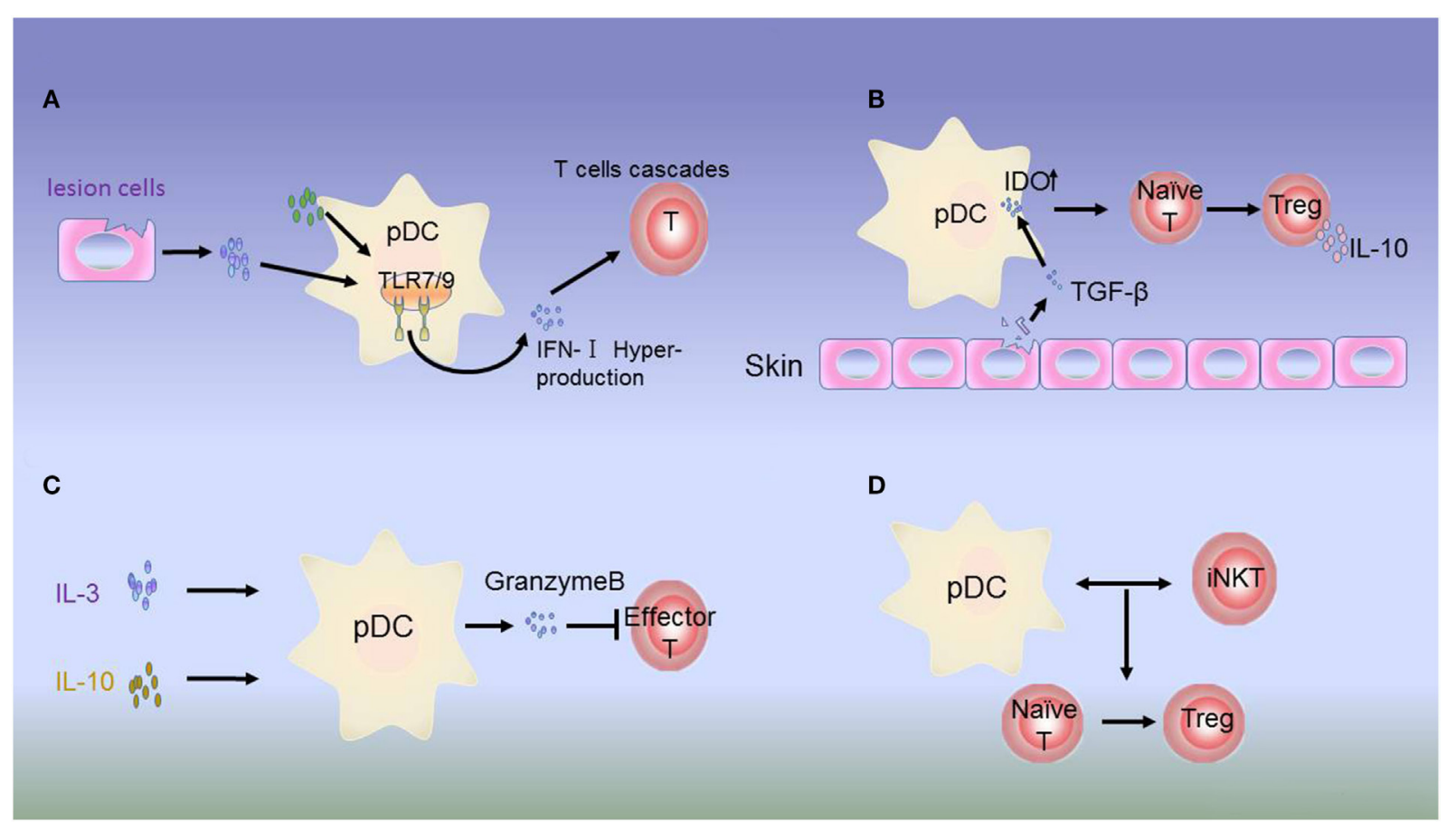

FIGURE 2 | Dysregulation of plasmacytoid dendritic cells (pDCs) in autoimmune disease. (A) Hyperproduction of type 1 interferon (IFN-I) by pDCs. In psoriasis, systemic lupus erythematosus (SLE), and most autoimmune inflammations, constitutive expression of toll-like receptor (TLR)-7/9 leads to excessive activation of pDCs in the skin of patients by molecules from lesion cells or autologous pDCs. IFN-I produced by pDCs initiates abnormal production of T cells.

(B) Immunosuppressive role of IDO. The inhibitory molecule IDO acts as a signaling protein in response to TGF- $\beta$, inducing the conversion of naive CD4+ and CD8 ${ }^{+} \mathrm{T}$ cells into Tregs. IDO can also dampen the antigen-presenting ability of pDCs. (C) In JIA, Tregs secrete low levels of IL-3 and IL-10. In response to these regulatory molecules, pDCs produce granzyme B to suppress the proliferation of effector T cells. (D) In type I diabetes (T1D), the interactions between pDCs and iNKT cells induce the $T$ cells to differentiate into Foxp3 ${ }^{+} \mathrm{CD} 4^{+}$Tregs.

TABLE 2 | Clinical trials of pDCs in various diseases.

\begin{tabular}{|c|c|c|c|c|c|}
\hline Target & Disease & Progress & Phase & Clinical trial no. & Combination \\
\hline \multirow[t]{3}{*}{ pDC vaccination } & Prostatic neoplasms & Recruiting & $\|$ & NCT02692976 & mDCs \\
\hline & Melanoma & Recruiting & $\|$ & NCT02574377 & mDCs \\
\hline & Melanoma & Completed & 1 & NCT01690377 & mDCs \\
\hline TLR-7 agonist & Cancer, melanoma & Ongoing & $\|$ & NCT00960752 & \\
\hline
\end{tabular}

After activation of the TLR-7/9 pathway, pDCs promote the secretion of cytokines and initiate the activation of NK cells and $\mathrm{CD}^{+} \mathrm{T}$ cells. Synthetic TLR-7/9 agonists as adjuvants to cancer vaccines are currently being tested in human clinical trials and in combination with conventional chemotherapy and other protocols (Table 2).

A previous report demonstrated that targeting pDCs with nanoparticles via the C-type lectin DEC-205, DC immunoreceptor, blood DC Ag-2, or the FcR CD32 led to uptake, processing, and (cross-)presentation of encapsulated Ag to both $\mathrm{CD}^{+}$and $\mathrm{CD}^{+} \mathrm{T}$ cells. Thus, these receptors may be viable candidates to target $\mathrm{pDCs}$ with nanocarriers. pDCs induce potent antitumor responses because of their crosspresentation capacity $(129,130)$.

Plasmacytoid dendritic cells produce a systemic type I IFN response, which is critical to NK activation and subsequent inhibition of tumor metastasis. When compared with pDCs isolated from peripheral blood, in vitro differentiated pDCs exhibit an increased capacity to induce NK cell-mediated killing in acute lymphoblastic leukemia (131). Moreover, mDCs and pDCs have also been successfully utilized in combination in clinical vaccination trials against melanoma, wherein both $\mathrm{mDCs}$ and $\mathrm{pDCs}$ were found to enhance NK cell cytotoxicity to reach optimal activity $(132,133)$. Combination vaccination with distinct DC subsets may be required to simultaneously promote $\mathrm{CD} 4^{+}, \mathrm{CD} 8^{+}$ T-cell, and NK-cell responses (134).

\section{Clinical}

Dendritic cell-based vaccines against cancer have also been developed during the past two decades. Clinical evidence showed that TAA-derived peptides loaded onto pDCs or CD1c ${ }^{+} \mathrm{DCs}$ achieve promising efficacy in patients with melanoma $(135,136)$. Confronting immune checkpoint inhibitors targeting CTLA4, PD1, and PD-L1 may lead to clinical benefits in patients with 
various types of cancers, and next-generation DC vaccines are expected be developed by integration of DC-based vaccines with combinatorial immunotherapy regimens (137).

Besides potential therapeutic applications in cancer, pDCs have also been shown to have important properties in autoimmune diseases. For example, pDCs are major immune contributors in lupus via IFN-I overexpression. Early studies have shown that congenic lupus-predisposed mice lack pDCs because of IRF8 deficiency or SLC15A4 mutation. Moreover, the results indicated absence of autoantibodies, reduced lymphadenopathy and splenomegaly, and extended survival. IRF8 and SLC15A4 may therefore be important targets for therapeutic intervention in lupus (40). Notably, both IRF8 and SLC15A4 are upstream molecules of the TLR pathway and are important for IFN secretion. As abnormal pDC activation and deregulated IFN-I production appear to be contributing factors in autoimmune disease pathogenesis, future studies should be performed to determine whether IFN-I blockade or pDC depletion would be an effective method for the treatment of autoimmune diseases (138).

Recent findings of DCs could make us redefine our perception of DC populations. For example, See's group defined a population of $\mathrm{CD} 123^{+} \mathrm{CD} 303^{+} \mathrm{CX} 3 \mathrm{CR} 1^{+} \mathrm{CD} 33^{+}$cells as $\mathrm{DC}$ precursors (pre-DCs), which share surface markers with classically defined pDCs and exhibit distinct functional properties. After removal of pre-DCs from the classically defined "pDC" population, the induction of $\mathrm{T}$-cell proliferation and production of T-cell stimulatory ligands by pDCs is decreased (139). Additionally, Villani et al. demonstrated six DC and four monocyte cell clusters using single-cell RNA-sequencing. The authors validated the presence of $\mathrm{Axl}^{+}$Siglec6 ${ }^{+}$DCs (AS DCs), which share transcriptional modules with classically defined "pDCs," but do not secrete IFN $\alpha$ and have stronger capacity to activate T cells (140). To date, pre-DCs and AS DCs have been shown to have similar functions; therefore, further studies are needed to verify their identities. The discovery of these two subtypes improves our understanding of classically defined pDCs, which

\section{REFERENCES}

1. Lennert K, Remmele W. [Karyometric research on lymph node cells in man. I. Germinoblasts, lymphoblasts \& lymphocytes]. Acta Haematol (1958) 19(2):99-113. doi:10.1159/000205419

2. Liu YJ. IPC: professional type 1 interferon-producing cells and plasmacytoid dendritic cell precursors. Annu Rev Immunol (2005) 23:275-306. doi:10.1146/ annurev.immunol.23.021704.115633

3. Swiecki M, Colonna M. The multifaceted biology of plasmacytoid dendritic cells. Nat Rev Immunol (2015) 15(8):471-85. doi:10.1038/nri3865

4. Manz MG, Traver D, Miyamoto T, Weissman IL, Akashi K. Dendritic cell potentials of early lymphoid and myeloid progenitors. Blood (2001) 97(11):3333-41. doi:10.1182/blood.V97.11.3333

5. Vermi W, Soncini M, Melocchi L, Sozzani S, Facchetti F. Plasmacytoid dendritic cells and cancer. JLeukoc Biol (2011) 90(4):681-90. doi:10.1189/ jlb.0411190

6. Chistiakov DA, Orekhov AN, Sobenin IA, Bobryshev YV. Plasmacytoid dendritic cells: development, functions, and role in atherosclerotic inflammation. Front Physiol (2014) 5:279. doi:10.3389/fphys.2014.00196

7. Watowich SS, Liu YJ. Mechanisms regulating dendritic cell specification and development. Immunol Rev (2010) 238(1):76-92. doi:10.1111/j.1600-065X. 2010.00949.x should be reconsidered based on the antigen presenting and cytokine-secretion functions of pDCs; the taxonomy may also need to be revised accordingly. These concepts are expected to facilitate more precise analyses of DC subset-specific targeting in health and disease.

Plasmacytoid dendritic cells are thought to be involved in the pathogenesis of a variety of diseases. Given the capacity of pDCs to easily switch phenotypes and functions according to disease microenvironmental signals, this plasticity may be harmful when disorders occur in individuals. In this review, we summarized the possible mechanisms of deterioration induced by pDCs. Different immunotherapeutic approaches, as well as combinations with other local or systemic disease therapies, may be required to realize synergistic benefits. Immunotherapy induced by pDCs will cover many nonclassic diseases. However, further clinical trials are necessary to identify the effective dose and criteria for suitable patients.

\section{AUTHOR CONTRIBUTIONS}

SL and JW carried out the primary literature search, wrote and revised the manuscript, created the illustrations, and contributed equally to the review. SZ and Y-JL involved in the preparation and revision of manuscript. JC initiated the concept and supervised the manuscript writing and revision. All authors read and approved the final manuscript.

\section{FUNDING}

This work was supported by the Key Scientific Project of Jilin Province (grant no. 20160520141JH), Youth Development Fund of the First Hospital of Jilin University (grant no. JDYY52015031), Platform Construction Project of Development and Reform Commission of Jilin Province (grant no. 2014N147), the National Natural Science Foundation of China (grant no. 81571534), and Program for JLU Science and Technology Innovative Research Team.

8. Helft J, Anjos-Afonso F, van der Veen AG, Chakravarty P, Bonnet D, Reis ESC. Dendritic cell lineage potential in human early hematopoietic progenitors. Cell Rep (2017) 20(3):529-37. doi:10.1016/j.celrep.2017.06.075

9. Sozzani S, Vermi W, Del Prete A, Facchetti F. Trafficking properties of plasmacytoid dendritic cells in health and disease. Trends Immunol (2010) 31(7):270-7. doi:10.1016/j.it.2010.05.004

10. Cella M, Jarrossay D, Facchetti F, Alebardi O, Nakajima H, Lanzavecchia A, et al. Plasmacytoid monocytes migrate to inflamed lymph nodes and produce large amounts of type I interferon. Nat Med (1999) 5(8):919-23. doi: $10.1038 / 11360$

11. Lombardi VC, Khaiboullina SF, Rizvanov AA. Plasmacytoid dendritic cells, a role in neoplastic prevention and progression. Eur J Clin Invest (2015) 45(Suppl 1):1-8. doi:10.1111/eci.12363

12. Huang XM, Liu XS, Lin XK, Yu H, Sun JY, Liu XK, et al. Role of plasmacytoid dendritic cells and inducible costimulator-positive regulatory $\mathrm{T}$ cells in the immunosuppression microenvironment of gastric cancer. Cancer Sci (2014) 105(2):150-8. doi:10.1111/cas.12327

13. Faget J, Bendriss-Vermare N, Gobert M, Durand I, Olive D, Biota C, et al. ICOS-ligand expression on plasmacytoid dendritic cells supports breast cancer progression by promoting the accumulation of immunosuppressive CD4+ T cells. Cancer Res (2012) 72(23):6130-41. doi:10.1158/0008-5472. CAN-12-2409 
14. Ciancanelli MJ, Huang SX, Luthra P, Garner H, Itan Y, Volpi S, et al. Infectious disease. Life-threatening influenza and impaired interferon amplification in human IRF7 deficiency. Science (2015) 348(6233):448-53. doi:10.1126/ science.aaa1578

15. Kim TW, Hong S, Lin Y, Murat E, Joo H, Kim T, et al. Transcriptional repression of IFN regulatory factor 7 by MYC is critical for type I IFN production in human plasmacytoid dendritic cells. J Immunol (2016) 197(8):3348-59. doi:10.4049/jimmunol.1502385

16. Colina R, Costa-Mattioli M, Dowling RJ, Jaramillo M, Tai LH, Breitbach CJ, et al. Translational control of the innate immune response through IRF-7. Nature (2008) 452(7185):323-8. doi:10.1038/nature06730

17. Sharma MD, Baban B, Chandler P, Hou DY, Singh N, Yagita H, et al. Plasmacytoid dendritic cells from mouse tumor-draining lymph nodes directly activate mature Tregs via indoleamine 2,3-dioxygenase. J Clin Invest (2007) 117(9):2570-82. doi:10.1172/JCI31911

18. Chen W, Liang X, Peterson AJ, Munn DH, Blazar BR. The indoleamine 2,3-dioxygenase pathway is essential for human plasmacytoid dendritic cell-induced adaptive $\mathrm{T}$ regulatory cell generation. J Immunol (2008) 181(8):5396-404. doi:10.4049/jimmunol.181.8.5396

19. Tsukamoto N, Okada S, Onami Y, Sasaki Y, Umezawa K, Kawakami Y. Impairment of plasmacytoid dendritic cells for IFN production by the ligand for immunoglobulin-like transcript 7 expressed on human cancer cells. Clin Cancer Res (2009) 15(18):5733-43. doi:10.1158/1078-0432.CCR-09-0171

20. Fabricius D, Neubauer M, Mandel B, Schutz C, Viardot A, Vollmer A, et al. Prostaglandin E2 inhibits IFN-alpha secretion and Th1 costimulation by human plasmacytoid dendritic cells via E-prostanoid 2 and E-prostanoid 4 receptor engagement. JImmunol (2010) 184(2):677-84. doi:10.4049/ jimmunol.0902028

21. Bekeredjian-Ding I, Schafer M, Hartmann E, Pries R, Parcina M, Schneider P, et al. Tumour-derived prostaglandin $\mathrm{E}$ and transforming growth factor-beta synergize to inhibit plasmacytoid dendritic cell-derived interferon-alpha. Immunology (2009) 128(3):439-50. doi:10.1111/j.1365-2567.2009.03134.x

22. Chauhan D, Singh AV, Brahmandam M, Carrasco R, Bandi M, Hideshima T, et al. Functional interaction of plasmacytoid dendritic cells with multiple myeloma cells: a therapeutic target. Cancer Cell (2009) 16(4):309-23. doi:10.1016/j.ccr.2009.08.019

23. Lee JW, Chung HY, Ehrlich LA, Jelinek DF, Callander NS, Roodman GD, et al. IL-3 expression by myeloma cells increases both osteoclast formation and growth of myeloma cells. Blood (2004) 103(6):2308-15. doi:10.1182/ blood-2003-06-1992

24. Schroeder JT, Bieneman AP, Xiao H, Chichester KL, Vasagar K, Saini S, et al. TLR9- and FcepsilonRI-mediated responses oppose one another in plasmacytoid dendritic cells by down-regulating receptor expression. J Immunol (2005) 175(9):5724-31. doi:10.4049/jimmunol.175.9.5724

25. Fabricius D, O'Dorisio MS, Blackwell S, Jahrsdorfer B. Human plasmacytoid dendritic cell function: inhibition of IFN-secretion and modulation of immune phenotype by vasoactive intestinal peptide. J Immunol (2006) 177(9):5920-7. doi:10.4049/jimmunol.177.9.5920

26. Dissanayake SK, Wade M, Johnson CE, O'Connell MP, Leotlela PD, French AD, et al. The Wnt5A/protein kinase $\mathrm{C}$ pathway mediates motility in melanoma cells via the inhibition of metastasis suppressors and initiation of an epithelial to mesenchymal transition. J Biol Chem (2007) 282(23):17259-71. doi:10.1074/jbc.M700075200

27. Hack K, Reilly L, Proby C, Fleming C, Leigh I, Foerster J. Wnt5a inhibits the CpG oligodeoxynucleotide-triggered activation of human plasmacytoid dendritic cells. Clin Exp Dermatol (2012) 37(5):557-61. doi:10.1111/ j.1365-2230.2012.04362.x

28. Demoulin S, Herfs M, Somja J, Roncarati P, Delvenne P, Hubert P. HMGB1 secretion during cervical carcinogenesis promotes the acquisition of a tolerogenic functionality by plasmacytoid dendritic cells. Int J Cancer (2015) 137(2):345-58. doi:10.1002/ijc.29389

29. Froidure A, Vandenplas O, D’Alpaos V, Evrard G, Pilette C. Defects in plasmacytoid dendritic cell expression of inducible costimulator ligand and IFN-alpha are associated in asthma with disease persistence. Am J Respir Crit Care Med (2015) 192(3):392-5. doi:10.1164/rccm.201503-0479LE

30. Ghirelli C, Reyal F, Jeanmougin M, Zollinger R, Sirven P, Michea P, et al. Breast cancer cell-derived GM-CSF licenses regulatory Th2 induction by plasmacytoid predendritic cells in aggressive disease subtypes. Cancer Res (2015) 75(14):2775-87. doi:10.1158/0008-5472.CAN-14-2386
31. Gerlini G, Urso C, Mariotti G, Di Gennaro P, Palli D, Brandani P, et al. Plasmacytoid dendritic cells represent a major dendritic cell subset in sentinel lymph nodes of melanoma patients and accumulate in metastatic nodes. Clin Immunol (2007) 125(2):184-93. doi:10.1016/ j.clim.2007.07.018

32. Aspord C, Leccia MT, Charles J, Plumas J. Plasmacytoid dendritic cells support melanoma progression by promoting Th2 and regulatory immunity through OX40L and ICOSL. Cancer Immunol Res (2013) 1(6):402-15. doi:10.1158/2326-6066.CIR-13-0114-T

33. Chevolet I, Speeckaert R, Schreuer M, Neyns B, Krysko O, Bachert C, et al. Clinical significance of plasmacytoid dendritic cells and myeloid-derived suppressor cells in melanoma. J Transl Med (2015) 13:9. doi:10.1186/ s12967-014-0376-x

34. Charles J, Di Domizio J, Salameire D, Bendriss-Vermare N, Aspord C, Muhammad R, et al. Characterization of circulating dendritic cells in melanoma: role of CCR6 in plasmacytoid dendritic cell recruitment to the tumor. J Invest Dermatol (2010) 130(6):1646-56. doi:10.1038/jid.2010.24

35. Conrad C, Gregorio J, Wang YH, Ito T, Meller S, Hanabuchi S, et al. Plasmacytoid dendritic cells promote immunosuppression in ovarian cancer via ICOS costimulation of Foxp3(+) T-regulatory cells. Cancer Res (2012) 72(20):5240-9. doi:10.1158/0008-5472.CAN-12-2271

36. Wei S, Kryczek I, Zou L, Daniel B, Cheng P, Mottram P, et al. Plasmacytoid dendritic cells induce $\mathrm{CD} 8+$ regulatory T cells in human ovarian carcinoma. Cancer Res (2005) 65(12):5020-6. doi:10.1158/0008-5472.CAN-04-4043

37. Labidi-Galy SI, Sisirak V, Meeus P, Gobert M, Treilleux I, Bajard A, et al. Quantitative and functional alterations of plasmacytoid dendritic cells contribute to immune tolerance in ovarian cancer. Cancer Res (2011) 71(16):5423-34. doi:10.1158/0008-5472.CAN-11-0367

38. Scott JL, Wirth JR, EuDaly JG, Gilkeson GS, Cunningham MA. Plasmacytoid dendritic cell distribution and maturation are altered in lupus prone mice prior to the onset of clinical disease. Clin Immunol (2017) 175:109-14. doi:10.1016/j.clim.2016.12.009

39. Ronnblom L, Eloranta ML, Alm GV. The type I interferon system in systemic lupus erythematosus. Arthritis Rheum (2006) 54(2):408-20. doi:10.1002/ art.21571

40. Baccala R, Gonzalez-Quintial R, Blasius AL, Rimann I, Ozato K, Kono DH, et al. Essential requirement for IRF8 and SLC15A4 implicates plasmacytoid dendritic cells in the pathogenesis of lupus. Proc Natl Acad Sci U S A (2013) 110(8):2940-5. doi:10.1073/pnas.1222798110

41. Khoryati L, Augusto JF, Shipley E, Contin-Bordes C, Douchet I, Mitrovic S, et al. IgE inhibits TLR-7 and -9 mediated expression of interferon-alpha by plasmacytoid dendritic cells in systemic lupus patients. Arthritis Rheumatol (2016) 68(9):2221-31. doi:10.1002/art.39679

42. Kavousanaki M, Makrigiannakis A, Boumpas D, Verginis P. Novel role of plasmacytoid dendritic cells in humans: induction of interleukin-10-producing Treg cells by plasmacytoid dendritic cells in patients with rheumatoid arthritis responding to therapy. Arthritis Rheum (2010) 62(1):53-63. doi:10.1002/art.25037

43. Lande R, Giacomini E, Serafini B, Rosicarelli B, Sebastiani GD, Minisola G, et al. Characterization and recruitment of plasmacytoid dendritic cells in synovial fluid and tissue of patients with chronic inflammatory arthritis. J Immunol (2004) 173(4):2815-24. doi:10.4049/jimmunol.173.4.2815

44. Shi W, Li X, Porter JL, Ostrodi DH, Yang B, Li J, et al. Level of plasmacytoid dendritic cells is increased in non-small cell lung carcinoma. Tumour Biol (2014) 35(3):2247-52. doi:10.1007/s13277-013-1297-7

45. Sorrentino R, Terlizzi M, Di Crescenzo VG, Popolo A, Pecoraro M, Perillo G, et al. Human lung cancer-derived immunosuppressive plasmacytoid dendritic cells release IL-1alpha in an AIM2 inflammasome-dependent manner. Am J Pathol (2015) 185(11):3115-24. doi:10.1016/j.ajpath.2015.07.009

46. Daissormont IT, Christ A, Temmerman L, Sampedro Millares S, Seijkens T, Manca M, et al. Plasmacytoid dendritic cells protect against atherosclerosis by tuning T-cell proliferation and activity. Circ Res (2011) 109(12):1387-95. doi:10.1161/CIRCRESAHA.111.256529

47. Macritchie N, Grassia G, Sabir SR, Maddaluno M, Welsh P, Sattar N, et al. Plasmacytoid dendritic cells play a key role in promoting atherosclerosis in apolipoprotein E-deficient mice. Arterioscler Thromb Vasc Biol (2012) 32(11):2569-79. doi:10.1161/ATVBAHA.112.251314

48. Grassia G, MacRitchie N, Platt AM, Brewer JM, Garside P, Maffia P. Plasmacytoid dendritic cells: biomarkers or potential therapeutic targets 
in atherosclerosis? Pharmacol Ther (2013) 137(2):172-82. doi:10.1016/j. pharmthera.2012.10.001

49. Yun TJ, Lee JS, Machmach K, Shim D, Choi J, Wi YJ, et al. Indoleamine 2,3-dioxygenase-expressing aortic plasmacytoid dendritic cells protect against atherosclerosis by induction of regulatory T cells. Cell Metab (2016) 23(5):852-66. doi:10.1016/j.cmet.2016.04.010

50. Lee JR, Dalton RR, Messina JL, Sharma MD, Smith DM, Burgess RE, et al. Pattern of recruitment of immunoregulatory antigen-presenting cells in malignant melanoma. Lab Invest (2003) 83(10):1457-66. doi:10.1097/ 01.LAB.0000090158.68852.D1

51. Movassagh M, Spatz A, Davoust J, Lebecque S, Romero P, Pittet M, et al. Selective accumulation of mature DC-Lamp+ dendritic cells in tumor sites is associated with efficient T-cell-mediated antitumor response and control of metastatic dissemination in melanoma. Cancer Res (2004) 64(6):2192-8. doi:10.1158/0008-5472.CAN-03-2969

52. Cao W, Bover L. Signaling and ligand interaction of ILT7: receptor-mediated regulatory mechanisms for plasmacytoid dendritic cells. Immunol Rev (2010) 234(1):163-76. doi:10.1111/j.0105-2896.2009.00867.x

53. Saadeh D, Kurban M, Abbas O. Plasmacytoid dendritic cell role in cutaneous malignancies. J Dermatol Sci (2016) 83(1):3-9. doi:10.1016/ j.jdermsci.2016.05.008

54. Gerlini G, Di Gennaro P, Mariotti G, Urso C, Chiarugi A, Pimpinelli N, et al. Indoleamine 2,3-dioxygenase+ cells correspond to the BDCA2+ plasmacytoid dendritic cells in human melanoma sentinel nodes. J Invest Dermatol (2010) 130(3):898-901. doi:10.1038/jid.2009.307

55. Chevolet I, Speeckaert R, Schreuer M, Neyns B, Krysko O, Bachert C, et al. Characterization of the in vivo immune network of IDO, tryptophan metabolism, PD-L1, and CTLA-4 in circulating immune cells in melanoma. Oncoimmunology (2015) 4(3):e982382. doi:10.4161/2162402X.2014.982382

56. Di Domizio J, Demaria O, Gilliet M. Plasmacytoid dendritic cells in melanoma: can we revert bad into good? J Invest Dermatol (2014) 134(7):1797-800. doi:10.1038/jid.2014.155

57. Castelli C, Triebel F, Rivoltini L, Camisaschi C. Lymphocyte activation gene-3 (LAG-3, CD223) in plasmacytoid dendritic cells (pDCs): a molecular target for the restoration of active antitumor immunity. Oncoimmunology (2014) 3(11):e967146. doi:10.4161/21624011.2014.967146

58. Chevolet I, Schreuer M, Speeckaert R, Neyns B, Hoorens I, van Geel N, et al. Systemic immune changes associated with adjuvant interferon-alpha2b-therapy in stage III melanoma patients: failure at the effector phase? Melanoma Res (2015) 25(4):357-61. doi:10.1097/CMR.0000000000000171

59. Ray A, Das DS, Song Y, Macri V, Richardson P, Brooks CL, et al. A novel agent SL-401 induces anti-myeloma activity by targeting plasmacytoid dendritic cells, osteoclastogenesis and cancer stem-like cells. Leukemia (2017). doi:10.1038/leu.2017.135

60. Ray A, Tian Z, Das DS, Coffman RL, Richardson P, Chauhan D, et al. A novel TLR-9 agonist C792 inhibits plasmacytoid dendritic cell-induced myeloma cell growth and enhance cytotoxicity of bortezomib. Leukemia (2014) 28(8):1716-24. doi:10.1038/leu.2014.46

61. Di Lullo G, Marcatti M, Heltai S, Brunetto E, Tresoldi C, Bondanza A, et al. Th22 cells increase in poor prognosis multiple myeloma and promote tumor cell growth and survival. Oncoimmunology (2015) 4(5):e1005460. doi:10.108 0/2162402X.2015.1005460

62. Ji P, Peterson LC. Plasmacytoid dendritic cells in chronic myelomonocytic leukemia. Blood (2014) 123(21):3220. doi:10.1182/blood-2014-03-557587

63. Saulep-Easton D, Vincent FB, Le Page M, Wei A, Ting SB, Croce CM, et al. Cytokine-driven loss of plasmacytoid dendritic cell function in chronic lymphocytic leukemia. Leukemia (2014) 28(10):2005-15. doi:10.1038/ leu.2014.105

64. Piechnik A, Dmoszynska A, Omiotek M, Mlak R, Kowal M, Stilgenbauer S, et al. The VEGF receptor, neuropilin-1, represents a promising novel target for chronic lymphocytic leukemia patients. Int J Cancer (2013) 133(6):1489-96. doi:10.1002/ijc. 28135

65. Gora-Tybor J, Blonski JZ, Robak T. Circulating vascular endothelial growth factor (VEGF) and its soluble receptors in patients with chronic lymphocytic leukemia. Eur Cytokine Netw (2005) 16(1):41-6.

66. Sawant A, Ponnazhagan S. Role of plasmacytoid dendritic cells in breast cancer bone dissemination. Oncoimmunology (2013) 2(2):e22983. doi:10.4161/ onci. 22983
67. Sisirak V, Vey N, Goutagny N, Renaudineau S, Malfroy M, Thys S, et al. Breast cancer-derived transforming growth factor-beta and tumor necrosis factor-alpha compromise interferon-alpha production by tumor-associated plasmacytoid dendritic cells. Int J Cancer (2013) 133(3):771-8. doi:10.1002/ ijc. 28072

68. Sisirak V, Faget J, Gobert M, Goutagny N, Vey N, Treilleux I, et al. Impaired IFN-alpha production by plasmacytoid dendritic cells favors regulatory T-cell expansion that may contribute to breast cancer progression. Cancer Res (2012) 72(20):5188-97. doi:10.1158/0008-5472.CAN-11-3468

69. Faget J, Sisirak V, Blay JY, Caux C, Bendriss-Vermare N, Menetrier-Caux C. ICOS is associated with poor prognosis in breast cancer as it promotes the amplification of immunosuppressive $\mathrm{CD} 4 \mathrm{~T}$ cells by plasmacytoid dendritic cells. Oncoimmunology (2013) 2(3):e23185. doi:10.4161/onci.23185

70. Pinto A, Rega A, Crother TR, Sorrentino R. Plasmacytoid dendritic cells and their therapeutic activity in cancer. Oncoimmunology (2012) 1(5):726-34. doi:10.4161/onci.20171

71. Anjubault T, Martin J, Hubert FX, Chauvin C, Heymann D, Josien R. Constitutive expression of TNF-related activation-induced cytokine (TRANCE)/receptor activating NF-kappaB ligand (RANK)-L by rat plasmacytoid dendritic cells. PLoS One (2012) 7(3):e33713. doi:10.1371/journal. pone. 0033713

72. Sawant A, Hensel JA, Chanda D, Harris BA, Siegal GP, Maheshwari A, et al. Depletion of plasmacytoid dendritic cells inhibits tumor growth and prevents bone metastasis of breast cancer cells. J Immunol (2012) 189(9):4258-65. doi:10.4049/jimmunol.1101855

73. Sawant A, Deshane J, Jules J, Lee CM, Harris BA, Feng X, et al. Myeloid-derived suppressor cells function as novel osteoclast progenitors enhancing bone loss in breast cancer. Cancer Res (2013) 73(2):672-82. doi:10.1158/0008-5472. CAN-12-2202

74. Curiel TJ, Cheng P, Mottram P, Alvarez X, Moons L, Evdemon-Hogan M, et al. Dendritic cell subsets differentially regulate angiogenesis in human ovarian cancer. Cancer Res (2004) 64(16):5535-8. doi:10.1158/0008-5472. CAN-04-1272

75. Zou W, Machelon V, Coulomb-L'Hermin A, Borvak J, Nome F, Isaeva T, et al. Stromal-derived factor-1 in human tumors recruits and alters the function of plasmacytoid precursor dendritic cells. Nat Med (2001) 7(12):1339-46. doi:10.1038/nm1201-1339

76. Khan WN, Li X, Xu Y, Ma L, Sun L, Fu G, et al. 17ß-estradiol enhances the response of plasmacytoid dendritic cell to CpG. PLoS One (2009) 4(12):e8412. doi:10.1371/journal.pone.0008412

77. Yang M, Yang L, Wang X, Wang Y, Wei Y, Zhao Y. Decline of plasmacytoid dendritic cells and their subsets in normal pregnancy are related with hormones. J Reprod Med (2015) 60(9-10):423-9.

78. Laffont S, Rouquie N, Azar P, Seillet C, Plumas J, Aspord C, et al. $\mathrm{X}$-chromosome complement and estrogen receptor signaling independently contribute to the enhanced TLR7-mediated IFN-alpha production of plasmacytoid dendritic cells from women. J Immunol (2014) 193(11):5444-52. doi:10.4049/jimmunol.1303400

79. Michel KG, Huijbregts RP, Gleason JL, Richter HE, Hel Z. Effect of hormonal contraception on the function of plasmacytoid dendritic cells and distribution of immune cell populations in the female reproductive tract. J Acquir Immune Defic Syndr (2015) 68(5):511-8. doi:10.1097/ QAI.0000000000000531

80. Laffont S, Seillet C, Guery JC. Estrogen receptor-dependent regulation of dendritic cell development and function. Front Immunol (2017) 8:108. doi:10.3389/fimmu.2017.00108

81. Pelka K, Latz E. IRF5, IRF8, and IRF7 in human pDCs - the good, the bad, and the insignificant? Eur J Immunol (2013) 43(7):1693-7. doi:10.1002/ eji.201343739

82. Susanne Beckebaum XZ, Chen X, Yu Z, Frilling A, Dworacki G, GrosseWilde $\mathrm{H}$, et al. Increased levels of interleukin-10 in serum from patients with hepatocellular carcinoma correlate with profound numerical deficiencies and immature phenotype of circulating dendritic cell subsets. Clin Cancer Res (2004) 10(21):7260-9.

83. Pedroza-Gonzalez A, Zhou G, Vargas-Mendez E, Boor PP, Mancham S, Verhoef $\mathrm{C}$, et al. Tumor-infiltrating plasmacytoid dendritic cells promote immunosuppression by $\operatorname{Tr} 1$ cells in human liver tumors. Oncoimmunology (2015) 4(6):e1008355. doi:10.1080/2162402X.2015.1008355 
84. Thordardottir S, Schaap N, Louer E, Kester MG, Falkenburg JH, Jansen J, et al. Hematopoietic stem cell-derived myeloid and plasmacytoid DC-based vaccines are highly potent inducers of tumor-reactive $\mathrm{T}$ cell and NK cell responses ex vivo. Oncoimmunology (2017) 6(3):e1285991. doi:10.1080/21 62402X.2017.1285991

85. Gai XD, Song Y, Li C, Lei YM, Yang B. Potential role of plasmacytoid dendritic cells for FOXP3 + regulatory T cell development in human colorectal cancer and tumor draining lymph node. Pathol Res Pract (2013) 209(12):774-8. doi:10.1016/j.prp.2013.08.011

86. Rega A, Terlizzi M, Luciano A, Forte G, Crother TR, Arra C, et al. Plasmacytoid dendritic cells play a key role in tumor progression in lipopolysaccharide-stimulated lung tumor-bearing mice. JImmunol (2013) 190(5):2391-402. doi:10.4049/jimmunol.1202086

87. Terzoglou AG, RoutsiasJG, Moutsopoulos HM, Tzioufas AG. Characterization of BDCA1 and BDCA4 dendritic cell subsets in rheumatoid arthritis patients. Arthritis Res Ther (2004) 6(Suppl 1):1. doi:10.1186/ar1043

88. Richez C, Schaeverbeke T, Dumoulin C, Dehais J, Moreau JF, Blanco P. Myeloid dendritic cells correlate with clinical response whereas plasmacytoid dendritic cells impact autoantibody development in rheumatoid arthritis patients treated with infliximab. Arthritis Res Ther (2009) 11(3):R100. doi:10.1186/ar2746

89. Jongbloed SL, Lebre MC, Fraser AR, Gracie JA, Sturrock RD, Tak PP, et al. Enumeration and phenotypical analysis of distinct dendritic cell subsets in psoriatic arthritis and rheumatoid arthritis. Arthritis Res Ther (2006) 8(1):R15. doi:10.1186/ar1864

90. Blomberg S, Eloranta ML, Magnusson M, Alm GV, Ronnblom L. Expression of the markers BDCA-2 and BDCA-4 and production of interferon-alpha by plasmacytoid dendritic cells in systemic lupus erythematosus. Arthritis Rheum (2003) 48(9):2524-32. doi:10.1002/art.11225

91. Kwok SK, Lee JY, Park SH, Cho ML, Min SY, Park SH, et al. Dysfunctional interferon-alpha production by peripheral plasmacytoid dendritic cells upon Toll-like receptor-9 stimulation in patients with systemic lupus erythematosus. Arthritis Res Ther (2008) 10(2):R29. doi:10.1186/ar2382

92. Leskela S, Rodriguez-Munoz A, de la Fuente H, Figueroa-Vega N, Bonay P, Martin P, et al. Plasmacytoid dendritic cells in patients with autoimmune thyroid disease. J Clin Endocrinol Metab (2013) 98(7):2822-33. doi:10.1210/ jc. 2013-1273

93. Villada G, Vega F. Clusters of paracortical plasmacytoid dendritic cells in lupus lymphadenitis. Blood (2017) 129(13):1884. doi:10.1182/ blood-2016-10-745463

94. Saadeh D, Kurban M, Abbas O. Update on the role of plasmacytoid dendritic cells in inflammatory/autoimmune skin diseases. Exp Dermatol (2016) 25(6):415-21. doi:10.1111/exd.12957

95. Walsh NM, Lai J, Hanly JG, Green PJ, Bosisio F, Garcias-Ladaria J, et al. Plasmacytoid dendritic cells in hypertrophic discoid lupus erythematosus: an objective evaluation of their diagnostic value. J Cutan Pathol (2015) 42(1):32-8. doi:10.1111/cup.12416

96. Dargent JL, Henne S, Pranger D, Balzarini P, Sartenaer D, Bulliard G, et al. Tumor-forming plasmacytoid dendritic cells associated with myeloid neoplasms. Report of a peculiar case with histopathologic features masquerading as lupus erythematosus. J Cutan Pathol (2016) 43(3):280-6. doi:10.1111/ cup. 12639

97. Albanesi C, Scarponi C, Pallotta S, Daniele R, Bosisio D, Madonna S, et al. Chemerin expression marks early psoriatic skin lesions and correlates with plasmacytoid dendritic cell recruitment. J Exp Med (2009) 206(1):249-58. doi:10.1084/jem.20080129

98. Vermi W, Riboldi E, Wittamer V, Gentili F, Luini W, Marrelli S, et al. Role of ChemR23 in directing the migration of myeloid and plasmacytoid dendritic cells to lymphoid organs and inflamed skin. J Exp Med (2005) 201(4):509-15. doi:10.1084/jem.20041310

99. Vermi W, Lonardi S, Morassi M, Rossini C, Tardanico R, Venturini M, et al. Cutaneous distribution of plasmacytoid dendritic cells in lupus erythematosus. Selective tropism at the site of epithelial apoptotic damage. Immunobiology (2009) 214(9-10):877-86. doi:10.1016/j.imbio.2009.06.013

100. von Glehn F, Santos LM, Balashov KE. Plasmacytoid dendritic cells and immunotherapy in multiple sclerosis. Immunotherapy (2012) 4(10):1053-61. doi:10.2217/imt.12.117

101. Sennikov SV, Falaleeva SA, Shkaruba NS, Chumasova OA, Obleukhova IA, Sizikov AE, et al. Maturation and cytokine production potential of dendritic cells isolated from rheumatoid arthritis patients peripheral blood and induced in vitro. Hum Immunol (2016) 77(10):930-6. doi:10.1016/j.humimm. 2016.07.005

102. Jongbloed SL, Benson RA, Nickdel MB, Garside P, McInnes IB, Brewer JM. Plasmacytoid dendritic cells regulate breach of self-tolerance in autoimmune arthritis. J Immunol (2009) 182(2):963-8. doi:10.4049/jimmunol.182.2.963

103. Jorgensen TN, Alfaro J, Enriquez HL, Jiang C, Loo WM, Atencio S, et al. Development of murine lupus involves the combined genetic contribution of the SLAM and FcgammaR intervals within the Nba2 autoimmune susceptibility locus. J Immunol (2010) 184(2):775-86. doi:10.4049/jimmunol.0901322

104. Kim JM, Park SH, Kim HY, Kwok SK. A plasmacytoid dendritic cells-type I interferon axis is critically implicated in the pathogenesis of systemic lupus erythematosus. Int J Mol Sci (2015) 16(6):14158-70. doi:10.3390/ ijms 160614158

105. Tian J, Avalos AM, Mao SY, Chen B, Senthil K, Wu H, et al. Toll-like receptor 9-dependent activation by DNA-containing immune complexes is mediated by HMGB1 and RAGE. Nat Immunol (2007) 8(5):487-96. doi:10.1038/ ni0707-780b

106. Menon M, Blair PA, Isenberg DA, Mauri C. A regulatory feedback between plasmacytoid dendritic cells and regulatory B cells is aberrant in systemic lupus erythematosus. Immunity (2016) 44(3):683-97. doi:10.1016/ j.immuni.2016.02.012

107. Bennett L, Palucka AK, Arce E, Cantrell V, Borvak J, Banchereau J, et al. Interferon and granulopoiesis signatures in systemic lupus erythematosus blood. J Exp Med (2003) 197(6):711-23. doi:10.1084/jem.20021553

108. Ching KH, Burbelo PD, Tipton C, Wei C, Petri M, Sanz I, et al. Two major autoantibody clusters in systemic lupus erythematosus. PLoS One (2012) 7(2):e32001. doi:10.1371/journal.pone.0032001

109. Lande R, Gregorio J, Facchinetti V, Chatterjee B, Wang YH, Homey B, et al. Plasmacytoid dendritic cells sense self-DNA coupled with antimicrobial peptide. Nature (2007) 449(7162):564-9. doi:10.1038/nature06116

110. Liu J, Zhang P, Morokuma K, Sharma RD. A new mechanism for the production of highly vibrationally excited $\mathrm{OH}$ in the mesosphere: an ab initio study of the reactions of O2(A 3Sigmau+ and A' 3Deltau)+H. J Chem Phys (2005) 122(10):104315. doi:10.1063/1.1862233

111. Loschko J, Heink S, Hackl D, Dudziak D, Reindl W, Korn T, et al. Antigen targeting to plasmacytoid dendritic cells via Siglec-H inhibits Th cell-dependent autoimmunity. J Immunol (2011) 187(12):6346-56. doi:10.4049/ jimmunol.1102307

112. Gilliet M, Conrad C, Geiges M, Cozzio A, Thurlimann W, Burg G, et al. Psoriasis triggered by toll-like receptor 7 agonist imiquimod in the presence of dermal plasmacytoid dendritic cell precursors. Arch Dermatol (2004) 140(12):1490-5. doi:10.1001/archderm.140.12.1490

113. Charles J, Chaperot L, Salameire D, Di Domizio J, Aspord C, Gressin R, et al. Plasmacytoid dendritic cells and dermatological disorders: focus on their role in autoimmunity and cancer. Eur J Dermatol (2010) 20(1):16-23. doi:10.1684/ejd.2010.0816

114. Gilliet M, Liu YJ. Generation of human CD8 T regulatory cells by CD40 ligand-activated plasmacytoid dendritic cells. J Exp Med (2002) 195(6): 695-704. doi:10.1084/jem.20011603

115. Jahrsdorfer B, Vollmer A, Blackwell SE, Maier J, Sontheimer K, Beyer T, et al. Granzyme B produced by human plasmacytoid dendritic cells suppresses T-cell expansion. Blood (2010) 115(6):1156-65. doi:10.1182/ blood-2009-07-235382

116. Salvi V, Vermi W, Cavani A, Lonardi S, Carbone T, Facchetti F, et al. IL-21 may promote granzyme B-dependent NK/plasmacytoid dendritic cell functional interaction in cutaneous lupus erythematosus. J Invest Dermatol (2017) 137(7):1493-500. doi:10.1016/j.jid.2017.03.016

117. Guery L, Hugues S. Tolerogenic and activatory plasmacytoid dendritic cells in autoimmunity. Front Immunol (2013) 4:59. doi:10.3389/fimmu.2013.00059

118. Pallotta MT, Orabona C, Volpi C, Vacca C, Belladonna ML, Bianchi R, et al. Indoleamine 2,3-dioxygenase is a signaling protein in long-term tolerance by dendritic cells. Nat Immunol (2011) 12(9):870-8. doi:10.1038/ni.2077

119. Diana J, Brezar V, Beaudoin L, Dalod M, Mellor A, Tafuri A, et al. Viral infection prevents diabetes by inducing regulatory T cells through NKT cell-plasmacytoid dendritic cell interplay. J Exp Med (2011) 208(4):729-45. doi:10.1084/ jem.20101692

120. Diana J, Griseri T, Lagaye S, Beaudoin L, Autrusseau E, Gautron AS, et al. NKT cell-plasmacytoid dendritic cell cooperation via OX40 controls viral 
infection in a tissue-specific manner. Immunity (2009) 30(2):289-99. doi:10.1016/j.immuni.2008.12.017

121. Diana J, Simoni Y, Furio L, Beaudoin L, Agerberth B, Barrat F, et al. Crosstalk between neutrophils, B-1a cells and plasmacytoid dendritic cells initiates autoimmune diabetes. Nat Med (2013) 19(1):65-73. doi:10.1038/nm.3042

122. Yamahira A, Narita M, Iwabuchi M, Uchiyama T, Iwaya S, Ohiwa R, et al. Activation of the leukemia plasmacytoid dendritic cell line PMDC05 by Toho-1, a novel IDO inhibitor. Anticancer Res (2014) 34(8):4021-8.

123. Le Mercier I, Poujol D, Sanlaville A, Sisirak V, Gobert M, Durand I, et al. Tumor promotion by intratumoral plasmacytoid dendritic cells is reversed by TLR7 ligand treatment. Cancer Res (2013) 73(15):4629-40. doi:10.1158/ 0008-5472.CAN-12-3058

124. Wu J, Li S, Yang Y, Zhu S, Zhang M, Qiao Y, et al. TLR-activated plasmacytoid dendritic cells inhibit breast cancer cell growth in vitro and in vivo. Oncotarget (2016) 8(7):11708-18. doi:10.18632/oncotarget.14315

125. Palamara F, Meindl S, Holcmann M, Luhrs P, Stingl G, Sibilia M. Identification and characterization of pDC-like cells in normal mouse skin and melanomas treated with imiquimod. J Immunol (2004) 173(5):3051-61. doi:10.4049/ jimmunol.173.5.3051

126. Urosevic M, Dummer R, Conrad C, Beyeler M, Laine E, Burg G, et al. Disease-independent skin recruitment and activation of plasmacytoid predendritic cells following imiquimod treatment. J Natl Cancer Inst (2005) 97(15):1143-53. doi:10.1093/jnci/dji207

127. Drobits B, Holcmann M, Amberg N, Swiecki M, Grundtner R, Hammer M, et al. Imiquimod clears tumors in mice independent of adaptive immunity by converting pDCs into tumor-killing effector cells. J Clin Invest (2012) 122(2):575-85. doi:10.1172/JCI61034

128. Liu C, Lou Y, Lizee G, Qin H, Liu S, Rabinovich B, et al. Plasmacytoid dendritic cells induce NK cell-dependent, tumor antigen-specific $\mathrm{T}$ cell cross-priming and tumor regression in mice. JClin Invest (2008) 118(3):1165-75. doi:10.1172/JCI33583

129. Tel J, Sittig SP, Blom RA, Cruz LJ, Schreibelt G, Figdor CG, et al. Targeting uptake receptors on human plasmacytoid dendritic cells triggers antigen cross-presentation and robust type I IFN secretion. JImmunol (2013) 191(10):5005-12. doi:10.4049/jimmunol.1300787

130. Tel J, Benitez-Ribas D, Hoosemans S, Cambi A, Adema GJ, Figdor CG, et al. DEC-205 mediates antigen uptake and presentation by both resting and activated human plasmacytoid dendritic cells. Eur J Immunol (2011) 41(4):1014-23. doi:10.1002/eji.201040790

131. Diaz-Rodriguez Y, Cordeiro P, Belounis A, Herblot S. In vitro differentiated plasmacytoid dendritic cells as a tool to induce anti-leukemia activity of natural killer cells. Cancer Immunol Immunother (2017) 66:1307. doi:10.1007/ s00262-017-2022-y

132. van Beek JJ, Gorris MA, Skold AE, Hatipoglu I, Van Acker HH, Smits EL, et al. Human blood myeloid and plasmacytoid dendritic cells cross activate each other and synergize in inducing NK cell cytotoxicity. Oncoimmunology (2016) 5(10):e1227902. doi:10.1080/2162402X.2016.1227902

133. Piccioli D, Sammicheli C, Tavarini S, Nuti S, Frigimelica E, Manetti AG, et al. Human plasmacytoid dendritic cells are unresponsive to bacterial stimulation and require a novel type of cooperation with myeloid dendritic cells for maturation. Blood (2009) 113(18):4232-9. doi:10.1182/ blood-2008-10-186890

134. Berraondo P, Labiano S, Minute L, Etxeberria I, Vasquez M, Sanchez-Arraez A, et al. Cellular immunotherapies for cancer. Oncoimmunology (2017) 6(5):e1306619. doi:10.1080/2162402X.2017.1306619

135. Abhishek DG, Marco S, Patrizia A, Laurence Z, Guido K, Lorenzo G. Trial watch: dendritic cell-based anticancer immunotherapy. Oncoimmunology (2017) 6(7):e1328341. doi:10.1080/2162402X.2017.1328341

136. Tel J, Aarntzen EH, Baba T, Schreibelt G, Schulte BM, Benitez-Ribas D, et al. Natural human plasmacytoid dendritic cells induce antigen-specific T-cell responses in melanoma patients. Cancer Res (2013) 73(3):1063-75. doi:10.1158/0008-5472.CAN-12-2583

137. Garg AD, Coulie PG, Van den Eynde BJ, Agostinis P. Integrating next-generation dendritic cell vaccines into the current cancer immunotherapy landscape. Trends Immunol (2017) 38(8):577-93. doi:10.1016/j.it.2017. 05.006

138. Santana-de Anda K, Gomez-Martin D, Soto-Solis R, Alcocer-Varela J. Plasmacytoid dendritic cells: key players in viral infections and autoimmune diseases. Semin Arthritis Rheum (2013) 43(1):131-6. doi:10.1016/j. semarthrit.2012.12.026

139. See P, Dutertre CA, Chen J. Mapping the human DC lineage through the integration of high-dimensional techniques. Science (2017) 356(6342):eaag3009. doi:10.1126/science.aag3009

140. Villani AC, Satija R. Single-cell RNA-seq reveals new types of human blood dendritic cells, monocytes, and progenitors. Science (2017) 356(6335):aah4573. doi:10.1126/science.aah4573

Conflict of Interest Statement: Y-JL is employed by Sanofi Research and Development, USA. The role of this author was revising the manuscript. All authors declare no competing interests.

The reviewer $\mathrm{MH}$ and handling editor declared their shared affiliation.

Copyright $\odot 2017 \mathrm{Li}, \mathrm{Wu}, \mathrm{Zhu}$, Liu and Chen. This is an open-access article distributed under the terms of the Creative Commons Attribution License (CC BY) The use, distribution or reproduction in other forums is permitted, provided the original author(s) or licensor are credited and that the original publication in this journal is cited, in accordance with accepted academic practice. No use, distribution or reproduction is permitted which does not comply with these terms. 